\title{
Design of Internet-based Enterprise Accident Information Platform
}

\author{
Zhengyu Cai ${ }^{1}$, Tan Yang ${ }^{1,2 *}$, Bin $\mathrm{Liu}^{3}$, Yafeng Zhou ${ }^{1}$, Yuefang $\mathrm{Li}^{1}$, Hao Wu ${ }^{1}$, Rong Yang ${ }^{1}$, Xiaoxi Zheng ${ }^{1}$, Pan Wang ${ }^{4}$ \\ ${ }^{1}$ College of Civil and Environmental Engineering, Anhui Xinhua University, Hefei, 230088, China; \\ ${ }^{2}$ State Key Laboratory of Fire Science, University of Science and Technology of China, Hefei 230026, China; \\ ${ }^{3}$ Sinopec Ningbo Engineering Co., Ltd., Ningbo, 315103, China; \\ ${ }^{4}$ Hefei Yaoan Technology Co., Ltd., Heifei,230000, China.
}

\begin{abstract}
Using Internet HAT information collection process to collect data, through Internet technologies suchas mobile law enforcement equipment and automatic identification software for major hazards to promote the formation of unified and standardized information security inspection, using the functions of synchronous interactive sharing and collaborative office between APP data and PC management data of mobile intelligent terminal, the accident information data is stored and managed in the Internet cloud, and an accident information sharing platform based on mobile intelligent terminal_government client_enterprise clien_related service agency client is built. It realizes the three-dimensional prevention and control network of fixed-point monitoring, mobile law enforcement, enterprise self-check and self-report production safety management, and provides strong technical suppor and service for Science and technology maintaining security.
\end{abstract}

\section{Introduction}

In the past, the collection of accident information often relies on people's routine management and efforts, but the types of data collected often cover a narrow range, only the accident cases which have a larger impact. Secondly, the update of laws and regulations, the investigation of potential accidents and other data are relatively single, unable to share resources and information between enterprises and other institutions, and the government. At the same time, in the process of internal security law enforcement inspection, the vast majority of them are based on personnel experience to carry out hidden danger investigation. Usually, there are problems of long inspection time, unreasonable basis and non-standard law enforcement process. In addition, the causes of potential accidents and corrective measures can not be shared with the enterprise safety management department at the first time, thus unable to provide scientific decision-making data for safety management to formulate the next round of law enforcement program adjustment.

The establishment of enterprise accident information platform is not only focused on the statistics of death and serious injury cases, but also on the use of mobile intelligent terminals for accident detection, the use of mobile law enforcement equipment and wireless printers to complete the entry and disposal of law enforcement information in the process of security law enforcement, and the on-site printing and electronic signature, and then through the combination of online and offline work mode. It makes the hidden danger information feedback to the relevant departments in time, ensures the efficiency of safety supervision, and effectively improves the safety supervision of enterprises and their own safety production level.

\section{Framework Flow of Enterprise Accident Information Platform}

As shown in Figure 1, the government-level clients focus on other organizations such as domestic companies, insurance companies, relevant state departments, associations and organizations, while participating in the integration of government safety rectification notification documents and accident investigation reports issued by nearby companies and associations to conduct statistical preservation.

Enterprise clients collect information about accidents in operation workshops for various construction projects through related on-line sensors and intelligent monitoring system. Mainly includes plant workshop, construction site online monitoring staff, equipment hidden dangers, faults and accident information; On-line sensors of relevant companies collect the hidden danger information of the surrounding environment and production, logistics and warehousing process of the company's construction operation platform; Enterprise operation and equipment management department online monitoring equipment hidden dangers and fault information, through different types of environment and types of HAT information collected to build enterprise HAT database, to provide

\footnotetext{
*Corresponding author's e-mail: jzaqyhj@163.com
} 
enterprise accident information management center timely and effectively first-hand accident information, to build enterprise accident information platform and promote safety inspection information management has a greater role.

Mobile Intelligent Terminal opens mobile security guard APP, clicks "My Task" and then "Starts Inspection". According to the responsibility system, labor protection, dangerous chemicals management and other inspection categories, they are checked one by one to determine whether the specific inspection items are qualified. For the unqualified points, they are taken photos on the spot and archive them. After the inspection is completed, the on-site inspection law enforcement documents are generated. The law enforcement data are uploaded to the accident information management center in time and can be shared between APP and PC.

Enterprise accident information platform through mobile intelligent terminal APP data and PC management data synchronous interactive sharing and collaborative office functions, on-site printing of the results of on-site processing, standardized law enforcement behavior, improved law enforcement efficiency and quality, and strengthened trace management.

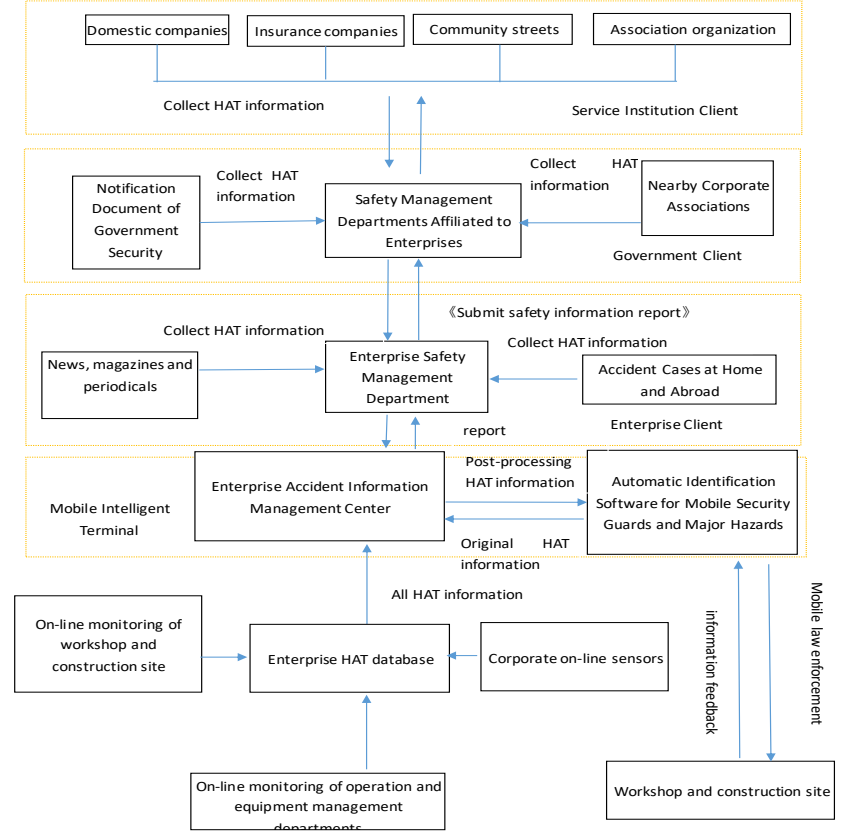

Figure 1. Framework flow of enterprise accident information platform

\section{Design of Enterprise Accident Information Platform}

\subsection{Statistics and Sharing of Safety Accident I nformation}

Safety accident information statistics uses HAT information collection process. As shown in Figure 1, a visual data sharing system is established for accident information statistics through mobile intelligent terminal, government client, enterprise client and service organization client as a whole. At the same time, cloud accident information resources are shared and interoperable by using Internet to statistics accident information.

Figure 2 is HAT information flow chart. For collecting HAT information, it is necessary to use the Internet to store information. While storing optical discs, the concept of cloud data processing on the Internet is used to store accident information. Instant messaging is used to enable multiple people to use the Internet to transmit text, images and other accident information in a timely manner. All departments and units need to establish a unified network workstation to share accident information synchronously. For important accident information to be notified within the enterprise, and submitted to the workshop backup, so as to facilitate the work unit to retrieve accident information.

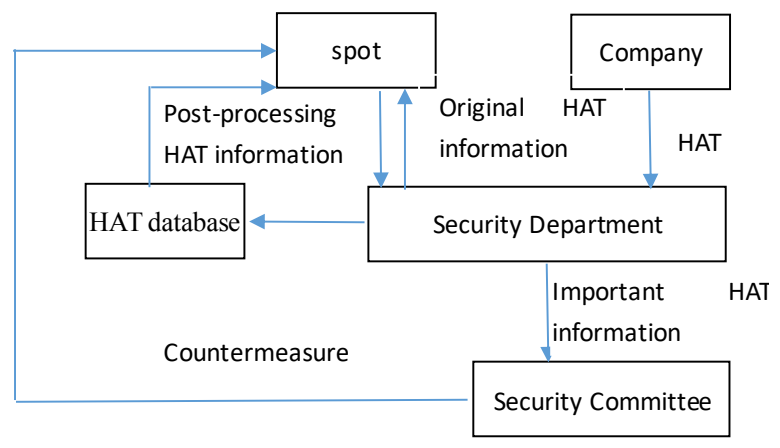

Figure 2. HAT information flow diagram

\subsection{Information Management of Safety Accidents}

An important part of enterprise accident information platform is enterprise accident information management center. Its function is to store uniformly laws and regulations information, accident hidden danger investigation information, accident cases, equipment failure information and HAT information database collected by enterprise's own departments shared with other client clouds. Based on the enterprise accident information management center, it covers 151 enterprises under 20 categories in the national economic industry classification, combs more than 25,000 hidden danger investigation items, more than 3,000 accident cases, more than 4,000 laws and regulations, and ensures that the data are updated and improved at the same time.

According to the information frontier technologies such as Internet of Things, Cloud Computing, Big Data Processing, Hot Spot Delivery and so on, the latest and most complete data information is provided for mobile intelligent terminals. Based on cloud data service system of information management center, products automatically detect data changes and automatically update data synchronously based on wireless networks such as $\mathrm{WiFi}$ and $3 \mathrm{G}$ to ensure the data integrity and timeliness of mobile terminals. 


\subsection{Design of Full Information Security Inspection}

In the design of enterprise accident information platform, the construction of fully informationized safety inspection design is based on the accident information classified by the enterprise accident information management center. It classifies and sorts out the hidden danger units, uses the relevant Internet technology such as the identification software of major hazards to carry out informationized safety inspection in construction site and workshop, and will be checked out through the mobile intelligent terminal (Mobile Security Guard). Safety information is fed back to the enterprise accident information management center and shared with other clients.

\section{Internet technologies such as automatic identification software for major hazards}

\subsection{Application of Automatic Identification Software for Major Hazard Sources}

The design of the software for automatic identification of major hazards is based on the Internet technology to improve the information technology of safety production in enterprises. What is needed is the strong technical capability of enterprises in the field of chemical hazard classification. The difficulty of the software design is how to classify the hazards of non-listed chemicals and any mixture chemicals automatically, and how to identify the hazards automatically by the hazard identification formula of various products unit.

In the process of designing full-information safety inspection, using Internet technology such as automatic identification software of major hazard sources, we can identify major hazard sources of chemicals in factory area, which greatly simplifies the identification process of chemical hazard sources in factory area, promotes the informatization process of safety inspection, and provides professional and technical knowledge support for building full-information safety inspection of enterprises.

\subsection{Application of Mobile Security Guards}

Mobile security guard is an Internet technology product based on mobile phone, tablet phone and other mobile intelligent terminal system platforms. Through inquiring the basic information of enterprises in product research and development, enforcing the law according to national laws and regulations and standards, and other functional products, it provides the necessary data support for law enforcement inspection and daily learning inquiry of grass-roots law enforcement personnel. In strict compliance with relevant laws and regulations on safety in production, relevant law enforcement inspection forms are made, relevant law enforcement basis and penalty measures are provided, and the exercise of power by law enforcement personnel at the grass-roots level is standardized so as to ensure that law enforcement inspection is justified and lawful.

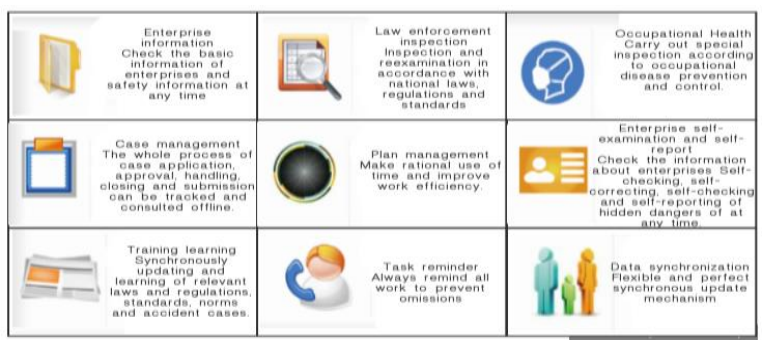

Figure 3. Functional effect diagram of mobile security guard

Figure 3 is the functional efficiency map of the mobile security guard. By updating and perfecting the laws and regulations in line with the national regulations at any time, and relevant safety operation rules and systems in line with the national and industrial standards, the products form a strong knowledge base system of software, which can provide strong knowledge support of laws, regulations and safety expertise for law enforcement and inspection sites, avoid blindness in the process of law enforcement and inspection. At the same time, the product realizes menu-based and navigation-based law enforcement inspection and review, which helps to improve the ability of grass-roots security supervisors to identify hidden dangers on the spot; secondly, using mobile security guards to query basic information of enterprises, hidden danger self-examination information and historical law enforcement inspection records information from time to time, which helps law enforcement personnel to understand the enterprise's file information comprehensively; Finally, the function of data synchronization perfects the synchronization update mechanism to a great extent, which enables the information of accident hidden danger to be uploaded to $\mathrm{PC}$ in time, and enables enterprises to monitor the accident hidden danger in time, take corrective measures in time and monitor whether it is implemented in place.

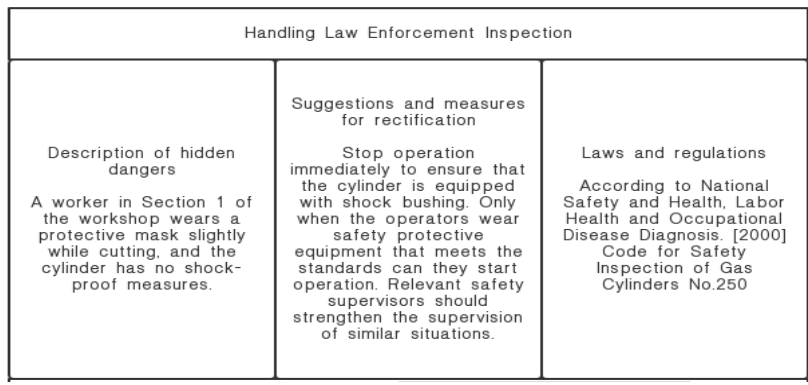

Figure 4. Mobile Law Enforcement Inspection Chart

Figure 4 is the use of mobile security guards for law enforcement inspection, through the installation of mobile security guards mobile phones, tablets and other mobile intelligent terminal equipment for site and operation workshop safety inspection activities, using the law enforcement inspection interface in software design, during the inspection process, facing hidden problems in 
the mobile terminal operation interface for problem description, risk classification, and give corrective measures opinions, to divide responsibility and what kind of punishment facilities and punishment basis to take, and can add on-site hidden danger map to make targeted treatment, so that in the safety inspection to achieve a law-based, evidence-based, more standardized law enforcement process also avoids the "human relations bill" with field personnel, according to the standardized "rectification bill" can more highlight the seriousness of security law enforcement.

The construction of enterprise accident information platform mainly makes other organizations, government level, enterprise level and mobile intelligent terminal form a sharing and interoperable platform of accident hidden danger information. The design of full-information security inspection is to use mobile security guards as the main body of information architecture transmission, and to interconnect with PC through APP data of software, synchronous monitoring of hidden danger factors and timely corrective measures can be achieved. On-site mobile security guards have realized the whole process of law enforcement, forensics collection, electronic and information management, supported on-site production and issuance of law enforcement documents, standardized law enforcement information, standardized law enforcement behavior, standardized law enforcement process, and realized the management mechanism of control in law enforcement and inspection and investigation afterwards.

\section{Conclusion}

The establishment of enterprise accident information platform can realize the interconnection and interoperability of safety production information between enterprises and government, service agencies and mobile intelligent terminals, effectively share and improve cross-departmental collaboration ability. Meanwhile it can realize a series of functions, such as safety supervision and law enforcement plan formulation, on-site mobile law enforcement, government verification, hidden danger investigation, hidden danger rectification, hidden danger reporting, daily safety inspection, occupational health supervision and management, special rectification, case handling and file management, and on the basis of enterprise classification, differentiated supervision of enterprises, it can effectively assist law enforcement personnel and enterprise safety management personnel to complete the daily safety supervision and law enforcement and hidden danger investigation and management related work, and effectively improve the government safety supervision and enterprise safety production level.

\section{Acknowledgments}

This research was financially supported by University Students Innovation and Entrepreneurship Training P rogram of Anhui Province (AH201712216082, AH20 1712216082), National College Students Innovation a nd Entrepreneurship Training Program (201812216044) and Anhui Xinhua University Natural Science Resea rch Project (2018zr017).

\section{Reference}

1. Xujiang. Safety Management. Beijing: Aviation Industry Press, 1993, 21 (3); 1-3.

2. Chang Zhanli. Basic Theory and Technology of Safety Management. Beijing: Metallurgical Industry Press, 2007, 23-45.

3. Luo Yun. Modern Safety Management. Beijing: Chemical Industry Press, 2004:50.

4. Zhu Jinzhi. Smart Cloud Computing. Beijing: Electronic Industry Press, 2010, 33.

5. Lakuma Buya. Cloud Computing-Principles and Paradigms. Li Hongjun, Translated, Beijing: Machinery Industry Press, 2013:27-40.

6. Victor Mayer-Schoenberg. Big Data Age. Sheng Yang-yan, Translated, Hangzhou: Zhejiang People's Publishing House, 2013:76.

7. Tan Y, Ya-Long J, Sudi G. Design of Underground Integrated Corridor Monitoring System in Yude Road, Liupanshui City[J]. Journal of Zhejiang University of Water Resources and Electric Power, 2017,29(04):56-59.

8. Tan Y, Ya-Long J, Rui W. Research on Operation Reliability for Refuge Capsule Oxygen Supply System Based on HEART[A]. 2018 3rd International Conference on Electrical, Mechanical and Computer Engineering Singapore[C]: MES Press, 2018:11-19.

9. Chow W K, Ng M Y. Fire risk to a local shopping mall[J]. International Journal of Risk Assessment and Management, 2002, 3(2/3/4):152-169(18).

10. Youn H, Hwang Y, Kwon Y. A Study of Density of the Person in a Classroom for Building Evacuation Safety Regulations in Korea[M]. Pedestrian and Evacuation Dynamics. Springer US, 2011.

11. Erika Choe), Myeonghee Seong). A Case Study of the Flipped Classroom in a Korean University General English Course[J]. Journal of Pan-Pacific Association of Applied Linguistics, 2016, 20.

12. Oliveira M C. A Bag-of-Tasks approach to speed up the lung nodules retrieval in the BigData age $[\mathrm{C}] / /$ IEEE 15th International Conference on e-Health Networking, Applications \& Services (Healthcom). IEEE, 2013.

13. Holland M, Hoggarth A, Nicholson J. Hydrographic processing considerations in the "Big Data" age: An overview of technology trends in ocean and coastal surveys[J]. IOP Conference Series: Earth and Environmental Science, 2016, 34(1):012016. 
14. Cui Q, Gang S. Research on design of geological mineral exploration enterprise coordinated management information platform[C]// Robotics \& Applications. 2012. 